\title{
MORPHOMETRY AND SURGICAL IMPORTANCE OF FORAMEN
} MAGNUM

\author{
Arora Sandeep *1, Sanjay Kumar Sharma ${ }^{2}$, Sadiq Wadood Siddiqui ${ }^{3}$, Simmi Khatri ${ }^{4}$. \\ ${ }^{* 1}$ Associate Professor, Department of Anatomy, Rajshree M edical Research Institute, Bareily, UP, \\ India. \\ ${ }^{2,3}$ Assistant Professor, Department of Anatomy, Rajshree Medical Research Institute, Bareily, UP, \\ India.
}

${ }^{4}$ Gynecologist, Medical Officer, M ohali, Chandigarh, India.

\section{ABSTRACT}

Introduction: The Foramen Magnum (FM) lies in an anteromedian position and leads into the posterior cranial
fossa. It is oval and wider behind, with its greatest diameter being anteroposterior. It contains the lower end of
the medulla oblongata, meninges, vertebral arteries and spinal accessory nerve. The apical ligament of dens
and the tectorial membrane pass through it, to attach to the basiocciput. Anteriorly the margin of foramen
magnum is slightly overlapped by the occipital condyles. Transcondylar, supracondylar, and other lateral
surgical approaches provide access to various foramina on the base of skull and prevent broad retraction of
the neural structures passing through them M orphometric analysis of foramen magnum plays important role
in transcondylar approach.
Aim: The study was designed to measure the diameters and shape of foramen Magnum and correlates the
measurements with clinical importance, as its shape and variation in diameters will be of great help to
operating surgeon during surgical procedures.
Materials and M ethods: Forty dry human skulls were studied during this research work. Skulls were taken from
the department of anatomy, dayanand medical college and hospital, Ludhiana and other medical college.
Results: During this study the mean M APD was $35.42 \mathrm{~mm}$, the M TD found to be $27.90 \mathrm{~mm}$ The Foramen magnum
Index found to be $17.20 \mathrm{~mm}$. The shape of foramen magnum found mostly was oval in $60 \%$ cases. The anterior
inter condylar distance found to be 18.01 to $20.00 \mathrm{~mm}$. Whereas middle intercondylar distance is 20.1 to $22 \mathrm{~mm}$
and posterior was 30.01 to $32.00 \mathrm{~mm}$.
Conclusion: The present study had observed the variation in the measurements of skull base foramen magnum
which were different from observations by the western studies because of difference of race and geographical
areas.
KEY worDS: Foramen Magnum, Base Of Skull, Morphometry, Skull Base.

Address for Correspondence: Dr Arora Sandeep, M S(Anatomy), Associate Professor, Department of Anatomy, Rajshree Medical Research Institute, Bareily, UP, India. Contact no.: 9814798755 E-Mail: drsamarora03@rediffmail.com

\begin{tabular}{|l|l|}
\multicolumn{3}{|c|}{ Access this Article online } \\
\hline Quick Response code & $\begin{array}{l}\text { Web site: International Journal of Anatomy and Research } \\
\text { ISSN 2321-4287 } \\
\text { www.ijmhr.org/ijar.htm }\end{array}$ \\
\cline { 2 - 3 } & \multicolumn{2}{c|}{$\begin{array}{l}\text { Accepted: 29 Sep 2016 } \\
\text { Dol: } 10.16965 / \text { ijar.2016.367 }\end{array}$} & $\begin{array}{l}\text { Received: 18 Aug 2016 } \\
\text { Peer Review: } 15 \text { Aug 2016 }\end{array}$ & $\begin{array}{l}\text { Published (O): 28 Feb } 2017 \\
\text { Published (P): 28 Feb } 2017\end{array}$ \\
\hline
\end{tabular}

\section{INTRODUCTION}

The skull is the most complex osseous structure in the body. The majority of bones in the skull are held together firmly by fibrous joints termed sutures. The bones forming the base of skull develop mainly by endochondral ossifica- tion, and also play an important part in the overall growth of the face and the neurocranium [1]. The skull base is a platform at the bottom of the cranium that cradles the brain, provides support, protection and serves as the entrance and exist for major vascular and neural structures [2]. 
It is well known that measurements of bone are useful in Anthropology [3]. Many important nerves and vessels pass in and out of the skull via openings termed foramina [1].

Cranial base dimensional anatomy is essential for quantitative distance evaluation of the structures in this complicated part of the skull and to facilitate the exposure of different foraminal regions [4].

The foramen magnum is an important landmark in the posterior part of the cranial base, which is largely formed by the occipital bone. It lies in an anteromedian position and leads into the posterior cranial fossa. It is oval and wider behind with its greatest diameter being anteroposterior. It contains the lower end ofthe medulla oblongata, meninges, vertebral arteries and spinal accessory nerve; the apical ligament of the dens and the tectorial membrane pass through it to attach to the internal basiocciput. Anteriorly, the margin of the foramen magnum is slightly overlapped by the occipital condyles, which project down to articulate with the superior articular facets on the lateral masses of the atlas $[5,6]$.

The foramen magnum (FM) lies in an anteromedian position and leads into the posterior cranial fossa. It is oval and wider behind, with its greatest diameter being anteroposterior. It contains the lower end of the medulla oblongata, meninges, vertebral arteries and spinal accessory nerve. The apical ligament of dens and the tectorial membrane pass through it, to attach to the basiocciput. Anteriorly the margin of foramen magnum is slightly overlapped by the occipital condyles [1].

Transcondylar, supracondylar, and other lateral surgical approaches provide access to various foramina on the base of skull and prevent broad retraction of the neural structures passing through them [7].

The transcondylar approach is being increasingly used to access lesions ventral to the brainstem and cervicomedullary junction. Understanding the bony anatomy of this region is important for this approach [8].

The space-occupying lesion ventral to the spinal canal at the level of the foramen magnum can be reached using a ventral or dorsal approach. The difficulties and high rate of morbidity associated with ventral approaches dictates to use a dorsal approach to the ventral processes of the foramen magnum. Such an approach needs a transcondylar approach. Partial resection of the occipital condyle, as made duringtranscondylar surgical approaches, has been an important step for access to the ventral and ventrolateral foramen magnum [9].

Advancements in micro surgical techniques have made possible the removal of advanced jugular foramen lesions, which were one assumed to be inoperable. As neuro Surgeons become bolder in approaching this region, so the need for familiarity with the detailed anatomy of this region becomes greater. The difficulties in exposing this foramen are created by its deep location $\&$ the surrounding vital structures, such as the carotid ortery anteriorly, the hypoglassal nerve medially, the facial nerve laterally and the vertebral artery inferiorly. All these important structures require careful dissection during access to this foramen [10].

M odern surgical procedure, anesthesia, as well as acupuncture practice, require more precise understanding of the surrounding anatomy of various foramina [11]. M any important nerves and vessels pass in and out of the skull via openings termed foramina [12].

Recent advances in CT have produced a growing need for precise information about optimal scanning positions for examining the morphological and metrical details of the foramina and canals in the base of the skull. Knowledge of the normal and variant positions of the canals and foramina of the skull base is important for radiologists, neurosurgeons and anatomists, because of the increasingly refined techniques available [3].

With the increasingly higher imaging capabilities of magnetic resonance imaging (MRI) and computed tomography (CT) foramina of the skulls are being seen as never before in living individuals. Evaluation of these foramina is becoming an important part of diagnostic medicine and making difficult diagnosis of pathological conditions of skull foramina possible [13].

Many clinical conditions have been associated 
with the variability in the dimensions of skull foramina which cause state of mental agony and night marish experience for patient as well as his family. Neurofibromatosis type 1 is found to be associated with increase in size of foramina and erosion at the base of skull. Similarly stenosis of foramina at the skull base is associated with osteopetrosis. Other clinical conditions like metabolic disorders, achondroplasia, Crouzons syndrome are associated with variations in foramina [14].

As endoscopic surgeons become more comfortable working along the skull base and beyond the skull base, they develop increased ability to recent and repair larger, more difficult lesions. In addition, rhinologists and otolaryngologists are increasingly called on by neurosurgical colleagues to endoscopically repair SB defects and CSF leaks after craniotomies and other neurosurgical procedures. Endoscopic repair of SB defects continues to be a preferred approach with a success rates of $90 \%$ [15].

\section{MATERIALS AND METHODS}

Forty human skulls, available in the Department of Anatomy, Dayanand Medical College and Hospital, Ludhiana and other medical colleges were studied after approval of hospital Ethics Committee. All the skulls selected were dry, complete $\&$ showed normal anatomical features. Skulls showing pathological changes, evidence of any previous trauma or skeletal disorders were excluded from this study.

Foramen Magnum recognized visually. Shape, variation and inspected. All the measurements were taken with the help of Vernier Caliper, Divider and Scale. The raw data obtained was statistically analysed. Range, mean, standard deviation and standard error of mean were determined for each parameter. All values were compared with series of other workers to draw the conclusions.

The following parameters were taken:

\section{Foramen Magnum:}

Maximum Anteroposterior diameter: It is the maximum distance between two points, one at the anterior and one at the posterior margin of foramen magnum in the principal axis. It was measured with the help of vernier caliper and the measurements were recorded in millimeters.

Maximum Transverse diameter: It is the maximum distance between two points, on the lateral margins of the foramen magnum perpendicular to the anterposterior diameter recorded. It was measured with the help of vernier caliper and the measurements were recorded in millimeters.

Foramen Magnum Index: It was calculated, dividing the anteroposterior diameter by the transverse diameter.

Intercondylar distance of Occipital Condyles: It is the distance between two points, taken on each medial margin of the occipital condyle at its anterior, middle and posterior part. It was measured with the help of vernier caliper and the measurements were recorded in millimeters.

\section{RESULTS}

During this study the mean MAPD was 35.42 with standard deviation of 3.22 and range was 30.3-43.44. The MTD found to be 27.81 with standard deviation of 2.58 and range of 20.62 to 31.56. The Foramen Index found to be 17.16 with standard deviation of 1.56 and Range of 14.69 to 21.07. the shape of foramen magnum found mostly was oval in $60 \%$ cases and circular in $40 \%$ cases. The anterior inter condylar distance found to be 18.01 to 20.00 in maximum cases, where as middle inter condylar distance is 20.1 to 22 and posterior was 30.01 to $\mathrm{m} 32.00$ in maximum cases.

Table 1: M easurements of Foramen M agnum (in mm).

\begin{tabular}{|c|c|c|c|c|}
\hline Parameter & Mean & SD & Range & SEM \\
\hline MAPD & 35.42 & 3.22 & $30.3-43.44$ & 0.59 \\
\hline MTD & 27.81 & 2.58 & $20.62-31.56$ & 0.47 \\
\hline FMI & 17.16 & 1.56 & $14.69-21.07$ & 0.28 \\
\hline
\end{tabular}

Table 2: Distribution of range of MAPD of Foramen Magnum(in mm).

\begin{tabular}{c|c|c|c|}
\cline { 2 - 4 } & Range of MAPD & $\begin{array}{c}\text { No. of } \\
\text { specimens }\end{array}$ & $\begin{array}{c}\text { \%age of } \\
\text { specimens }\end{array}$ \\
\cline { 2 - 4 } Maximum & $30.01-32.00$ & 4 & 13.33 \\
\cline { 2 - 4 } number of \\
cases in each & $32.01-34.00$ & 6 & 20 \\
\cline { 2 - 4 } part is \\
\cline { 2 - 4 } highlighted. & $34.01-36.00$ & $\mathbf{7}$ & $\mathbf{2 3 . 3 3}$ \\
\cline { 2 - 4 } & $36.01-38.00$ & 6 & 20 \\
\cline { 2 - 4 } & $38.01-40.00$ & 5 & 16.67 \\
\cline { 2 - 4 } & $40.01-42.00$ & - & - \\
\cline { 2 - 4 } & $42.01-44.00$ & 2 & 6.67 \\
\hline Total & 30 & 100 \\
\hline
\end{tabular}


Table 3: Distribution of range of MTD of Foramen Magnum (in $\mathrm{mm}$ ).

\begin{tabular}{|c|c|c|}
\hline Range of M TD & $\begin{array}{c}\text { No. of } \\
\text { specimens }\end{array}$ & $\begin{array}{c}\text { \%age of } \\
\text { specimens }\end{array}$ \\
\hline $20.01-22.00$ & 1 & 3.33 \\
\hline $22.01-24.00$ & 1 & 3.33 \\
\hline $24.01-26.00$ & 4 & 13.33 \\
\hline $26.01-28.00$ & 7 & 23.34 \\
\hline $28.01-30.00$ & 9 & 30 \\
\hline $30.01-32.00$ & 8 & 26.67 \\
\hline Total & 30 & 100 \\
\hline
\end{tabular}

Maximum number of cases in each part is highlighted. Table 4: Shape of Foramen M agnum.

\begin{tabular}{|c|c|c|c|}
\hline Parameter & Shape & $\begin{array}{c}\text { No. of } \\
\text { specimens }\end{array}$ & $\begin{array}{c}\text { \%age of } \\
\text { specimen }\end{array}$ \\
\hline \multirow{2}{*}{ FM } & Circular & 12 & 40 \\
\cline { 2 - 4 } & Oval & $\mathbf{1 8}$ & $\mathbf{6 0}$ \\
\hline
\end{tabular}

Maximum number of cases in each part is highlighted. Table 5: Distribution of range of Foramen M agnum Index.

\begin{tabular}{|c|c|c|}
\hline Range of FMI & $\begin{array}{c}\text { No. of } \\
\text { specimens }\end{array}$ & $\begin{array}{c}\text { \%age of } \\
\text { specimen }\end{array}$ \\
\hline $14.01-15.00$ & 1 & 3.33 \\
\hline $15.01-16.00$ & 6 & 20 \\
\hline $16.01-17.00$ & $\mathbf{8}$ & $\mathbf{2 6 . 6 7}$ \\
\hline $17.01-18.00$ & 6 & 20 \\
\hline $18.01-19.00$ & 6 & 20 \\
\hline $19.01-20.00$ & 1 & 3.33 \\
\hline $20.01-21.00$ & 1 & 3.33 \\
\hline $21.01-22.00$ & 1 & 3.33 \\
\hline Total & 30 & 100 \\
\hline
\end{tabular}

Maximum number of cases in each part is highlighted Table 6: Measurements of Intercondylar Distance (in $\mathrm{mm}$ ).

\begin{tabular}{|c|c|c|c|c|}
\hline Parameter & Mean & SD & Range & SEM \\
\hline $\begin{array}{c}\text { Anterior Intercondylar } \\
\text { Distance }\end{array}$ & 17.25 & 1.91 & $11.78-19.80$ & 0.35 \\
\hline $\begin{array}{c}\text { Middle Intercondylar } \\
\text { Distance }\end{array}$ & 21.64 & 2.26 & $16.28-28.40$ & 0.41 \\
\hline $\begin{array}{c}\text { Posterior Intercondylar } \\
\text { Distance }\end{array}$ & 30.66 & 1.97 & $26.58-32.98$ & 0.35 \\
\hline
\end{tabular}

Table 7: Distribution of range of Anterior Intercondylar Distance (in $\mathrm{mm}$ ).

\begin{tabular}{|c|c|c|}
\hline $\begin{array}{c}\text { Range of Anterior } \\
\text { Intercondylar Distance }\end{array}$ & $\begin{array}{c}\text { No. of } \\
\text { specimens }\end{array}$ & $\begin{array}{c}\text { \%age of } \\
\text { specimens }\end{array}$ \\
\hline $10.01-12.00$ & 1 & 3.33 \\
\hline $12.01-14.00$ & - & - \\
\hline $14.01-16.00$ & 8 & 26.67 \\
\hline $16.01-18.00$ & 9 & 30 \\
\hline $18.01-20.00$ & $\mathbf{1 1}$ & $\mathbf{3 6 . 6 7}$ \\
\hline $20.01-22.00$ & 1 & 3.33 \\
\hline Total & 30 & 100 \\
\hline
\end{tabular}

M aximum number of cases in each part is highlighted.
Table 8: Distribution of range of Middle Intercondylar Distance (in $\mathrm{mm}$ ).

\begin{tabular}{|c|c|c|}
\hline $\begin{array}{c}\text { Range of M iddle } \\
\text { Intercondylar Distance }\end{array}$ & $\begin{array}{c}\text { No. of } \\
\text { specimens }\end{array}$ & $\begin{array}{c}\text { \%age of } \\
\text { specimens }\end{array}$ \\
\hline $16.01-18.00$ & 2 & 6.67 \\
\hline $18.01-20.00$ & 3 & 10 \\
\hline $20.01-22.00$ & $\mathbf{1 2}$ & $\mathbf{4 0}$ \\
\hline $22.01-24.00$ & 11 & 33.3 \\
\hline $24.01-26.00$ & 2 & 6.67 \\
\hline $26.01-28.00$ & - & - \\
\hline $28.01-30.00$ & 1 & 3.33 \\
\hline Total & 30 & 100 \\
\hline
\end{tabular}

Maximum number of cases in each part is highlighted.

Table 9: Distribution of range of Posterior Intercondylar Distance (in $\mathrm{mm}$ ).

\begin{tabular}{|c|c|c|}
\hline $\begin{array}{c}\text { Range of Posterior } \\
\text { Intercondylar Distance }\end{array}$ & $\begin{array}{c}\text { No. of } \\
\text { specimens }\end{array}$ & $\begin{array}{c}\text { \%age of } \\
\text { specimens }\end{array}$ \\
\hline $26.01-28.00$ & 2 & 6.67 \\
\hline $28.01-30.00$ & 10 & 33.3 \\
\hline $30.01-32.00$ & 11 & 36.67 \\
\hline $32.01-34.00$ & 6 & 20 \\
\hline $34.01-36.00$ & 1 & 3.33 \\
\hline Total & 30 & 100 \\
\hline
\end{tabular}

Maximum number of cases in each part is highlighted.

Fig. 1: Showing intercondylar (I/C) distance.

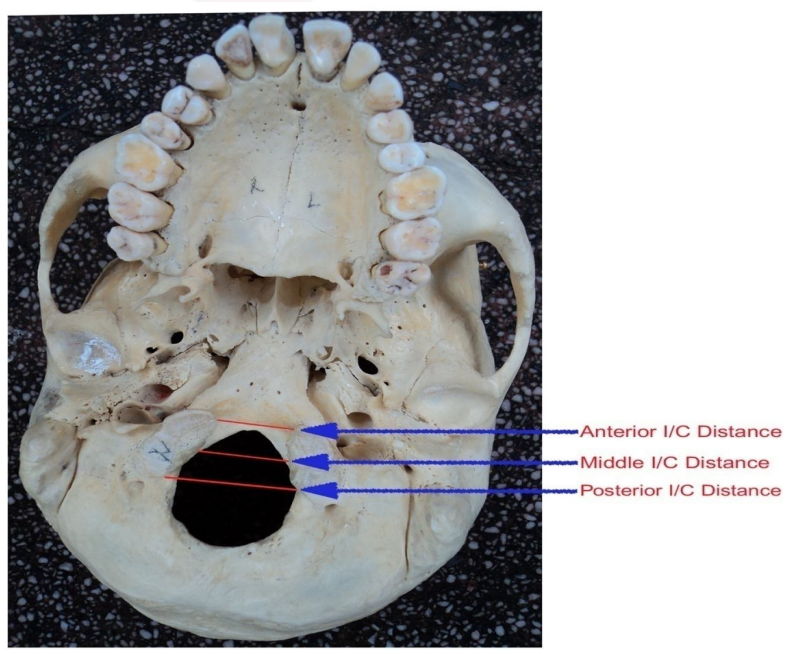

\section{DISCUSSION}

The overall goal of this study was to generate data that would be useful to the neurosurgeon and anaesthetic as an understanding of the anatomy of the location of skull foramina is essential for performing effective nerve block and avoiding injuries to the neurovascular bundles during neuro and orofacial surgeries. The study would also help the radiologist and oncologist to evaluate the tumor involvement of foramina on imaging. 
Table 10: Comparison of M APD of Foramen M agnum.

\begin{tabular}{|c|c|c|c|}
\hline Author & Year & Origin/ Race & $\begin{array}{c}\text { MAPD } \\
\text { (in mm) }\end{array}$ \\
\hline Berge et al [10] & 2001 & American & 33.8 \\
\hline Citardi et al [18] & 2001 & American & 33.52 \\
\hline Konig et al [18] & 2005 & German & $34.3+2.3$ \\
\hline Muthukumar et al [4] & 2005 & Indian & 33.3 \\
\hline Naderi et al [5] & 2005 & Turkish & $34.7+2.3$ \\
\hline Tubbs et al [17] & 2010 & Caucasians & 31 \\
\hline Present Study & 2010 & Indian & $35.38+3.22$ \\
\hline
\end{tabular}

The MAPD of FM in present study is $35.38+3.22 \mathrm{~mm}$ (Range $30.3-43.44 \mathrm{~mm}$ ). Table 10 compares the values with existing data. The MAPD of the Foramen Magnum in the present study is in harmony with the results of the previous studies, but has a little higher value.

Table 11: Comparison of M TD of Foramen M agnum.

\begin{tabular}{|c|c|c|c|}
\hline Author & Year & Origin/ Race & $\begin{array}{c}\text { MTD(in mm) } \\
\text { Mean+SD }\end{array}$ \\
\hline Berge et al [10] & 2001 & American & 28.3 \\
\hline Citardi et al [18] & 2001 & American & 28.88 \\
\hline Konig et al [18] & 2005 & German & $30.6+2.4$ \\
\hline Muthukumar et al [4] & 2005 & Indian & 27.9 \\
\hline Tubbs et al [17] & 2010 & Caucasians & 27 \\
\hline Present Study & 2010 & Indian & $27.81+2.58$ \\
\hline
\end{tabular}

Table 11 compares the values of M TD of FM with the previous studies. The M TD of FM in present study is $27.81+2.58 \mathrm{~mm}$ (Range $20.62-31.56 \mathrm{~mm}$ ). Similar results were obtained by Muthukumar et al and Tubbs et al. The results showed a lower value of M PD of FM in comparison with studies of Berge et al, Citardi et al and Konig et al.

Table 12: Shape of Foramen Magnum

\begin{tabular}{|c|c|c|c|c|}
\hline Author & Year & Origin/ Race & Circular (\%) & Oval (\%) \\
\hline Murshed et al [18] & 2003 & Turkish & 21.8 & 8.1 \\
\hline Konig et al [18] & 2005 & German & 25 & 25 \\
\hline Present study & 2010 & Indian & 40 & 60 \\
\hline
\end{tabular}

Table 12 compares the shape of Foramen Magnum with previous data. In present study $60 \%$ skulls have oval foramen magnum and $40 \%$ are circular which showed higher percentage as compared to previous studies.

Table 13: Comparison of Intercondylar Distance.

\begin{tabular}{|c|c|c|c|c|c|}
\hline \multirow{2}{*}{ Author } & \multirow{2}{*}{ Year } & \multirow{2}{*}{$\begin{array}{c}\text { Origin/ } \\
\text { Race }\end{array}$} & \multicolumn{3}{|c|}{$\begin{array}{c}\text { Intercondylar Distance (in mm) } \\
\text { Mean+SD }\end{array}$} \\
\cline { 4 - 6 } & & & Anterior & Middle & Posterior \\
\hline Naderi et al [5] & 2005 & Turkish & $21.0+2.8$ & & $41.6+2.9$ \\
\hline Konig et al [18] & 2005 & German & & $32.5+6.7$ & \\
\hline Harisudha et al [17] & 2010 & Indian & 20.2 & & 35.8 \\
\hline Present study & 2010 & Indian & $17.25+1.91$ & $21.64+2.26$ & $30.66+1.97$ \\
\hline
\end{tabular}

Int J Anat Res 2017, 5(1):3464-69. ISSN 2321-4287
Table 13 compares the values of Intercondylar Distance with the existing data. The anterior Intercondylar distance in present study is $17.25+1.91 \mathrm{~mm}$ (Range 11.78-19.80mm). Harisudha et al and Naderi et al had higher values for the anterior and posterior intercondylar distance. The middle Intercondylar distance in present study is $21.64+2.26 \mathrm{~mm}$ ( Range $16.28-28.4 \mathrm{~mm}$ ). Konig et al proposed higher values for the same. The posterior Intercondylar distance in present study is $30.66+1.97 \mathrm{~mm}$ (Range 26.58-32.98mm).

Foramen magnum is morphologically variable osteological feature in the skull which has undergone evolutionary changes [16-18]. There is great variation in the morphological types of foramen magnum. In the present study, the various variants (shapes) of foramen magnum were described as oval (60\%), rounded (40\%) (Table 13). The shape and morphological variations of foramen magnum are important in neurological interpretation. In an ovoid type of the foramen magnum, the surgeon may find it difficult to explore the anterior portion of the foramen magnum.

\section{CONCLUSION}

The present study had observed the variation in the measurements of skull base foramina which were differ from observations by the western studies because of difference of race and geographical areas. M orphometric analysis of foramen magnum plays important role in transcondylar approach. As observed during the study, by and large all the measurements of foramen magnum, which were taken, were found to be a few millimeters higher than the western population.

The present study was undertaken to gain information about the size of some important foramina of skull encountered commonly by neurosurgeons and anaesthetics in the Indian population. Knowledge of the normal and variant positions of the foramina of the skull base is important for radiologists, neurosurgeons and anatomists, because of the increasingly refined techniques available. This is significant as the outcomes of various surgical procedures depend upon the size and variations of these foramina. This knowledge also helps to choose the safe 
approach to these foramina and avoiding damage to the important neurovascular bundle which passes through them. The best selection of treatment depends on understanding the anatomy of the skull base foramina and relationship with other intracranial structures. These values could also be of forensic importance because of racial and ethnic variations.

\section{Conflicts of Interests: None}

\section{REFERENCES}

[1]. NemzekWR, BrodieHA, Hecht ST, Chong BW, Babcook C), Seibert JA. M R, CT, and Plain film imaging of the developing skull base in fetal specimens. AJNR. 2000; 21:1699-706.

[2]. Standring S. External skull. In: Standring S, Borley NR, Collins P, Crossman AR, Gatzoulis M A, Healy JC, et al. Gray's Anatomy: The Anatomical Basis of Clinical Practice. 40th ed. Elsevier Churchill Livingstone; 2008:409-21.

[3]. Karasu A, Cansever T, Batay F, Sabanci PA, Al-M efti O.The microsurgical anatomy of the hypoglossal canal. Surg Radiol Anat. 2009;31:363-7.

[4]. Muthukumar N, Swaminathan R, Venkatesh G, Bhanumathy SP. A morphometric analysis of the foramen magnum region as it relates to the transcondylar approach. Acta Neurochir (wien) 2005;147(8):889-95.

[5]. Naderi S, Korman E, Citak G, Guvencer M , Arman C, Senoglu M . et al. Morphometric analysis of human occipital condyle. Clinical neurology and neurosurgery 2005;107:191-9.

[6]. Idowu OE.The jugular foramen - a morphometric study. Folia Morphol. 2004;63(4):419-22.

[7]. Gusmao S,Oliveira M, Tazinaffo U, Honey CR. Percutaneous trigeminal nerve radiofrequency rhizotomy guided by computerized tomography fluoroscopy. J.Neurosurg 2003;99:785-6.
[8]. Elias M G, Silva RB, Pimentel ML, Cardoso VTS, Rivello T, Babinski MA. Morphometric analysis of the infraorbital foramen and accessories foraminas in Brazilian Skulls.Int J Morphol.2004;22(4):273-8.

[9]. Aziz SR, Marchena JM , Puran A. Anatomic characteristics of the infraorbital foramen: A cadaver study. J Oral Maxillofac Surg. 2000;58(9):992-6.

[10]. Berge JK, Bergman RA. Variations in size and in symmetry of foramina of the human skull. Clin Anat 2001;14:406-13.

[11]. Cicekcibasi AE, M urshed KA, Ziylan T, Seker M , Tuncer I. A morphometric evaluation of some important bony landmarks on the skull base related to sexes. Turk J Med Sci 2004;34:37-42.

[12]. Anand M K, Singh PR, Raibagkar CJ, Bhatt R. Comparison of foramina on both sides of dry human skulls. J Anat Soc India. 2002;51(1):131-2.

[13]. Anil Kumar, M itesh Dave, Sanam Anwar. M ORPHOMETRICEVALUATION OFFORAM EN M AGNUM IN DRY HUM AN SKULLS. Int J Anat Res 2015;3(2):1015-23.

[14]. Standarding S. Gray's anatomy. The anatomical basis of clinical practice. 39th ed. London: Elsevier Churchill Livingstone; 2005: 460.

[15]. Wise SK, Harvey RJ, Neal JG, Patel SJ, Frankel BM, Schlosser RJ. Factors contributing to failure in endoscopic skull base defect repair. Am J Rhinol Allergy. 2009;23(2):185-91.

[16]. Nevell L, Wood B. Cranial base evolution within the hominin clade. J Anat., 2008;212: 455-468.

[17]. Tubbs RS, Griessenauer C], Loukas M, Shoja MM, Cohen-Gadol AA. M orphometric analysis of the foramen magnum: an anatomic study. Neurosurgery. 2010 Feb 1;66(2):385-8.

[18]. M urshed KA, Çiçekcibaoi AE, Tuncer I. Morphometric evaluation of the foramen magnum and variations in its shape: a study on computerized tomographic images of normal adults. Turkish Journal of Medical Sciences. 2003 Sep 24;33(5):301-6.

How to cite this article:

Arora Sandeep, Sanjay Kumar Sharma, Sadiq Wadood Siddiqui, Simmi Khatri. M ORPHOM ETRY AND SURGICAL IM PORTANCE OF FORAMEN MAGNUM. Int J Anat Res 2017;5(1):3464-3469. Dol: 10.16965/ijar.2016.367 